\title{
Evaluation of Mechanical Properties of Nonsteroidal Anti-Inflammatory Matrix Type Transdermal Therapeutic Systems
}

\author{
Paula Antonoaea ${ }^{1}$, Nicoleta Todoran ${ }^{1 *}$, Emőke Rédai ${ }^{1}$, Adriana Ciurba ${ }^{1}$, Cătălina Bogdan², Mirela \\ Moldovan², Daniela Lucia Muntean ${ }^{3}$ \\ 1 Department of Pharmaceutical Technology, University of Medicine and Pharmacy of Tîrgu Mureș, Romania \\ 2 Department of Dermatopharmacy and Cosmetics, "luliu Hațieganu" University of Medicine and Pharmacy Cluj-Napoca, Romania \\ 3 Department of Analytical Chemistry and Drug Analysis, University of Medicine and Pharmacy of Tîrgu Mureș, Romania
}

Objective: Transdermal therapeutic systems (TTSs) represent an intensely studied alternative to oral delivery of non-steroid anti-inflammatory drugs (NSAIDs) in the treatment of rheumatic diseases due to its ability of avoiding the side effects of the oral route. This study aims to present the evaluation of the mechanical properties of three NSAIDs (meloxicam, tenoxicam and indomethacin) individually included in four type of polymeric matrixes, as part of new formulations development process. Methods: 12 products in form of TTS matrixes were prepared by solvent casting evaporation technique, using hydroxypropyl methylcellulose (HPMC 15000, HPMC E5) and/or ethylcellulose as matrix-forming polymers. Each of the resulted products was evaluated by determining the water vapor absorption, desorption or transmission in controlled atmosphere humidity (evaluation of porosity); the elongation capacity, tensile strength and bioadhesiveness (evaluation of mechanical properties). Results: The analysis of three groups of the experimental data expressed as averages on each group was necessary, in order to identify the parameters which statistically are critically influenced by the ingredients associated in the TTSs matrix compositions. Analysis by normality tests, variance and correlation tests (Anova, Pearson) enabled evaluation of the effect of NSAID type vs. the effect of polymer matrix type on the parameters of the NSAID TTS matrix. Conclusions: Meloxicam incorporated in the structure of HPMC 15000 polymeric matrix favors its viscoelastic structure. Ethylcellulose functions as plasticizer and supports the matrix bioadhesiveness. HPMC E5 does not meet the requirements for TTS preparation in the used experimental conditions.

Keywords: transdermal therapeutic system, matrix type, non-steroid anti-inflammatory, mechanical properties, bioadhesiveness

Received 28 February 2017 / Accepted 13 April 2017

\section{Introduction}

Transdermal therapeutic systems (TTSs) represent an important therapeutic progress for both healthcare professionals and patients, as the absorption of pharmaceutical active ingredients by the transdermal route has the main advantage of minimize their side effects [1-3]. The transdermal route is also preferable in case of oral intolerance, or to enable patients to self-administrate their medication [4]. Although the efficacy of nonsteroidal anti-inflammatory drugs (NSAIDs) in rheumatic diseases is well known, their gastric side effects cannot be neglected. Considering this, in the last years the interest to incorporate NSAIDs into TTSs has grown, as it results from the latest published data for: indomethacin $[5,6]$, meloxicam $[7,8]$, tenoxicam $[7,9]$, lornoxicam [10,11], naproxen [12], ketoprofen [13].

In order to study and describe the dissolution process of the active ingredient from a TTS, several properties of the matrix system need to be evaluated, such as: physical appearance, folding endurance, tensile strength, moisture vapors absorption, moisture vapors loss. These properties depend on the composition, compatibility and amount of used ingredients [14-16]. In addition, the ability of the NSAIDs to be released from a transdermal therapeutic system is fundamentally influenced by certain mechanical

* Correspondence to: Nicoleta Todoran

E-mail: nicoleta.todoran@umftgm.ro properties $[14,17]$ that must be provided to the bioadhesive matrix by a suitable formulation.

This study aims to present the evaluation of the mechanical properties of three NSAIDs individually included in four type of polymeric matrix, as part of the formulation development process of new TTSs.

\section{Methods}

\section{Preparation of NAIDs TTS matrix:}

-Chemicals: meloxicam - MX (Techno Drugs \& Intermediates Ltd. Mumbai, India), tenoxicam - TX (Nantong Chemding Chephar Co. Ltd. Jiangsu, China) and indomethacin - IND (Sigma Aldrich Milan, Italy). Three types of cellulose ethers polymers were used as matrix formers in ultrapure water (Millipore Direct-Q S. water distiller): hydroxypropyl methylcellulose - HPMC 15000 (Metolose 90SH - $15000 \mathrm{mPa} \cdot \mathrm{s}$, Shin-Etsu Chemical Co., Ltd. Tokyo, Japan), hydroxypropyl methylcellulose - HPMC E5 (Methocel E5 - $5 \mathrm{mPa} \cdot \mathrm{s}$, Dow Chemical Co., Midland, USA) and ethyl cellulose - EC 10 (EC $10 \mathrm{mPa} \cdot s$, Sigma Aldrich Co., Germany). Auxiliary substances: propylene glycol - PG (Scharlau Chemie, Barcelona, Spain); tween 20 (Sigma Aldrich Co., France); absolute ethanol and chloroform (Chemical Company, Romania).

-Formulation of NSAIDs TTS matrix: 12 compositions containing each $0.5 \%$ of NSAID were formulated using 
three different NSAIDs (MX, TX or IND), each of them being included in four variants of polymeric liquid dispersions (table I).

- TTS matrix preparation technique: $0.5 \%$ NSAID dissolved in ethanol - propylene was mixed with $1 \%$ tween 20 (previously dispersed in the corresponding amount of water). The film former polymer/s (dissolved in a minimum amount of chloroform, in the case of EC 10) has been added to the mixture under continuous stirring to obtain a homogeneous dispersion which was then poured into Petri dishes (diameter of $9.8 \mathrm{~cm}$ ) and kept 24 hours into an oven at $40^{\circ} \mathrm{C}$, for solvent evaporation.

Evaluation of bulk viscoelastic properties (sample sizelperformed test):

-Samples of $75.39 \mathrm{~cm}^{2}(\varnothing 9.8 \mathrm{~cm})$ : Physical appearance was visually evaluated in terms of appearance, color, clarity and smoothness of the surface. Weight uniformity $-m(g)$ was determined by weighing three samples of each product and then expressed as the calculated average. Thickness $-T$ $(\mathrm{mm})$ was determined using a digital micrometer and expressed as average of the values determined in five different points on the surface of the each product.

-Sample of $4.0 \mathrm{~cm}^{2}(2.0 \mathrm{~cm} / 2.0 \mathrm{~cm})$ : Folding endurance - FE $(x)$ was determined by repeatedly folding the sample (twice for a pair) in the same place (middle line) and expressed as the number (x) of fold pairs to which the product resisted until the break.

-Samples of $6 \mathrm{~cm}^{2}(4.0 \mathrm{~cm}$ length $1.5 \mathrm{~cm}$ width): Tensile strength - TS $\left(N \cdot \mathrm{mm}^{-2}\right)$ was determined by subjecting the sample, kept fixed at the upper end, to increasing downwards tensile forces generated by $10 \mathrm{~g}$ weights successively attached to the lower end, until the break of the sample. TS $\left(N \cdot m m^{-2}\right)=(M \cdot g) /(W \cdot T)$, wherein $M$ - is the weight that generated the tensile force $(\mathrm{Kg}), g$ - the gravitational acceleration $(9.8 \mathrm{~N} / \mathrm{Kg}), W$ - the width of sample $(\mathrm{mm})$ and $T$ - the thickness of sample (mm). Elongation to break - Eb (\%): $E b(\%)=\left(L_{f}-L_{i}\right) \cdot 100 / L_{i}$, wherein $L_{i}-$ is the initial length of sample $(\mathrm{cm})$ and $L_{f}$ - the final length of sample $(\mathrm{cm})$ recorded before break. The pairs of data (elongation as a result of tensile strength) recorded during each determination were then used to evaluate the viscoelastic behavior by graphical and statistical correlation analysis.

-Samples of $4.15 \mathrm{~cm}^{2}(\varnothing 2.3 \mathrm{~cm})$ : Moisture vapor absorption - WVA (\%) was determined by keeping the sample for 72 hours in desiccator containing a saturated solution of potassium chloride (relative humidity - $\mathrm{RH} \approx 80 \%$ ) and expressed as the moisture uptake: WVA $(\%)=\left(m_{f}\right.$ $\left.m_{i}\right) \cdot 100 / m_{i}$, wherein $m_{i}$ - is the initial mass of the sample (g), $m_{f}$ - the final mass of the sample (g). Moisture vapor loss - WVL (\%) was determined by keeping the sample for 72 hours in desiccator containing anhydrous calcium chloride $(\mathrm{RH} \approx 0 \%)$ and expressed as the calculated moisture lost: $\operatorname{WVL}(\%)=\left(m_{i}-m_{f}\right) \cdot 100 / m_{i}$, wherein $m_{i}$ - is the initial mass of the sample $(\mathrm{g}), m_{f}$ - the final mass of the sample (g). Water vapor transmission rate - WVTR $\left(g \cdot \mathrm{cm}^{-2} \cdot h^{-1}\right)$ was determined by weighting an assemble consisting of a glass flask (internal volume of $6 \mathrm{~cm}^{3}$ ) containing $1.000 \mathrm{~g}$ of anhydrous calcium chloride ( $\mathrm{RH} \approx 0 \%)$, with the opening sealed with the test sample, before and after maintaining it to constant mass $(72 \mathrm{~h})$ in a desiccator containing a saturated solution of potassium chloride $(\mathrm{RH} \approx 80 \%)$. WVTR $\left(g \cdot c m^{-2} \cdot h^{-1}\right)=\left(m_{f}-m_{i}\right) \cdot 100 / t \cdot S$, wherein $m_{i}$ - is the initial mass of the sample $(\mathrm{g}), m_{f^{-}}$the final mass of the sample $(\mathrm{g})$, $t$ - time $(72 \mathrm{~h})$ and $S$ - the surface of the sample $\left(4.15 \mathrm{~cm}^{2}\right)$.

Evaluation of texture and surface properties: was performed with a CT3 Texture Analyzer (Brookfield Engineering Laboratories, equipped with TexturePro CT V1.5 Software). For each sample, three measurements were carried out and the mean \pm standard deviation were reported.

-Hardness force (the resistance of TTS matrix to perforation) - Hf (g) was determined by running the Rupture Test in the following conditions: the sample placed between the two plates of the TA-FSF fixture; TA $42(3 \mathrm{~mm}$ Cylinder Probe) as penetration accessory device; target value -4500 $\mathrm{g}$, trigger load $-10 \mathrm{~g}$, test speed $-0.20 \mathrm{~mm} / \mathrm{sec}$; test target - Load (recorded value). One cycle includes all recordings until the rupture of the sample.

-Adhesiveness (the surface stickiness of TTS matrix) - A $(\mathrm{mJ})$ was measured based on the adhesive force - Af $(\mathrm{g}) \mathrm{de}-$ termined by running the Compression Test in the following conditions: the sample (at two minutes after wetting with $200 \mu \mathrm{L}$ distilled water) placed into TA-BT-KIT fixture; TA-AACC36 accessory device covered with a natural membrane (intestine porcine membrane); target value $100 \mathrm{~g}$, hold time - $10 \mathrm{sec}$, trigger load - $0.5 \mathrm{~g}$, test speed - 1 $\mathrm{mm} / \mathrm{sec}$; test target - Load (recorded value).

Statistical analysis: were performed with GraphPad Prism 6 (GraphPad Software, Inc., San Diego, California), considering the statistical significant difference at $\mathrm{p}<0.05$, for the confidence interval (CI) of $95 \%$. The calculated

Table I. Compositions containing $0.5 \%$ NSAID proposed in the study

\begin{tabular}{|c|c|c|c|c|c|c|c|c|c|c|c|c|}
\hline \multirow{2}{*}{ Ingredient (\%) } & \multicolumn{4}{|c|}{ Meloxicam } & \multicolumn{4}{|c|}{ Tenoxicam } & \multicolumn{4}{|c|}{ Indomethacin } \\
\hline & MX 1 & $M \times 2$ & $M \times 3$ & MX 4 & TX 1 & TX 2 & $T \times 3$ & TX 4 & IND 1 & IND 2 & IND 3 & IND 4 \\
\hline HPMC E5 & 3.0 & & - & & 3.0 & & & - & 3.0 & & & - \\
\hline HPMC 15000 & - & 1.0 & 1.5 & 1.0 & - & 1.0 & 1.5 & 1.0 & - & 1.0 & 1.5 & 1.0 \\
\hline${ }^{*} \mathrm{EC} 10$ & & & & 1.0 & & & & 1.0 & & & & 1.0 \\
\hline Ethanol - PG (3:1) & \multicolumn{12}{|c|}{40.0} \\
\hline Tween 20 & \multicolumn{12}{|c|}{1.0} \\
\hline Water & \multicolumn{12}{|c|}{ to 100.0} \\
\hline
\end{tabular}

*dissolved in a small amount of chloroform 
descriptive statistic parameters were the followings: arithmetic mean; standard deviation (SD) and coefficient of variation $(\mathrm{CV})$. In order to test the normality of the dispersion the following inferential tests were applied: KolmogorovSmirnov (KS), D'Agostino \& Pearson omnibus and ShapiroWilk. The variance analysis and the correlation for association between variables were quantified by: two-way Anova test, Tukey test, Pearson's correlation test.

\section{Results}

12 products in form of TTS matrix were prepared by casting on a circular surface of $75.39 \mathrm{~cm}^{2}$ each of the homogenous aqueous dispersions containing $0.5 \%$ NSAID (MX, TX or IND) in four variants of polymeric composition. The values of the determined parameters of these laboratory products are shown in table II and the texture and surface properties of NSAID TTS matrix prepared in the four polymeric films in table III.

\section{Discussion}

The TTSs were obtained as four matrix type (1-4) polymeric films with uniform, porous and lightly sticky surface. The greasy aspect of the EC 10 containing films (type 4) may be explained by the chloroform used to dissolve the polymer before incorporation. The color of the film depends on the NSAID type included in the matrix: those containing meloxicam (MX) are light yellow, tenoxicam (TX) intensive yellow, and indomethacin (IND) whiteyellow.

\section{Variance analysis of NSAID TTSs matrix parameters:}

Taking into account the variability of compositions, the analysis of three groups of the experimental data expressed as calculated arithmetic averages of data on each group was necessary, in order to identify the parameters (as dependent variables) which statistically are critically influenced by the ingredients associated in the TTSs matrix compositions (as independent variables). These grouped calculated data are shown in table IV.

-The effect of the formulation variables on parameters of the NSAID TTS matrix, based on the analysis of individual data (tables II-III) vs. the average of total products (table IV, group 1):

The average weight $(\mathrm{m})$ of the 12 products is $2.52 \pm$ $0.10 \mathrm{~g}$ to a surface of $75.39 \mathrm{~cm}^{2}(\varnothing 9.8 \mathrm{~cm})$ and the thickness $(\mathrm{T})$ is $0.32 \pm 0.04 \mathrm{~mm}$, favorable for cutaneous administration. The viscosifying capacity of the used HPMC type determines the mechanical resistance of the polymeric matrix. Films based on HPMC E5 have low mechanical resistance, making impossible to measure any elongation at tensile strength. Nevertheless, surface properties (hardness force and adhesiveness) were successfully determined, so the HPMC E5 films were kept in the study. HPMC 15000 combined or not with EC 10 confers flexibility and mechanical resistance (as FE > 150).

Table III. Texture and surface properties of NSAID TTS matrix

\begin{tabular}{lccc}
\hline TTS matrix & $\mathrm{Hf}(\mathrm{g}) \pm \mathrm{SD}$ & $\mathrm{Af}(\mathrm{g}) \pm \mathrm{SD}$ & $\mathrm{A}(\mathrm{mJ}) \pm \mathrm{SD}$ \\
\hline $\mathrm{MX} 1$ & $40.2 \pm 3.6$ & $60.5 \pm 23.0$ & $0.16 \pm 0.04$ \\
MX2 & $200.7 \pm 13.1$ & $147.1 \pm 26.1$ & $0.31 \pm 0.05$ \\
MX3 & $473.7 \pm 37.0$ & $75.7 \pm 26.7$ & $0.16 \pm 0.02$ \\
MX4 & $112.8 \pm 13.8$ & $185.7 \pm 1.0$ & $0.36 \pm 0.13$ \\
TX1 & $27.2 \pm 1.6$ & $83.7 \pm 12.9$ & $0.19 \pm 0.01$ \\
TX2 & $154.7 \pm 4.8$ & $184.3 \pm 14.0$ & $0.20 \pm 0.01$ \\
TX3 & $806.2 \pm 41.6$ & $63.5 \pm 5.3$ & $0.21 \pm 0.01$ \\
TX4 & $140.7 \pm 10.9$ & $93.2 \pm 44.9$ & $0.12 \pm 0.03$ \\
IND1 & $70.5 \pm 4.4$ & $125.8 \pm 11.3$ & $0.14 \pm 0.01$ \\
IND2 & $273.7 \pm 28$ & $83.5 \pm 32.8$ & $0.17 \pm 0.04$ \\
IND3 & $505.2 \pm 54.5$ & $97.3 \pm 21.8$ & $0.12 \pm 0.02$ \\
IND4 & $227.5 \pm 9.8$ & $93.0 \pm 25.2$ & $0.17 \pm 0.01$ \\
\hline
\end{tabular}

$\mathrm{Hf}=$ hardness force; $\mathrm{Af}=$ adhesive force; $\mathrm{A}=$ adhesiveness $\mathrm{SD}=$ standard deviation $(\mathrm{n}=3)$

Table II. Bulk viscoelastic properties of NSAID TTS matrix

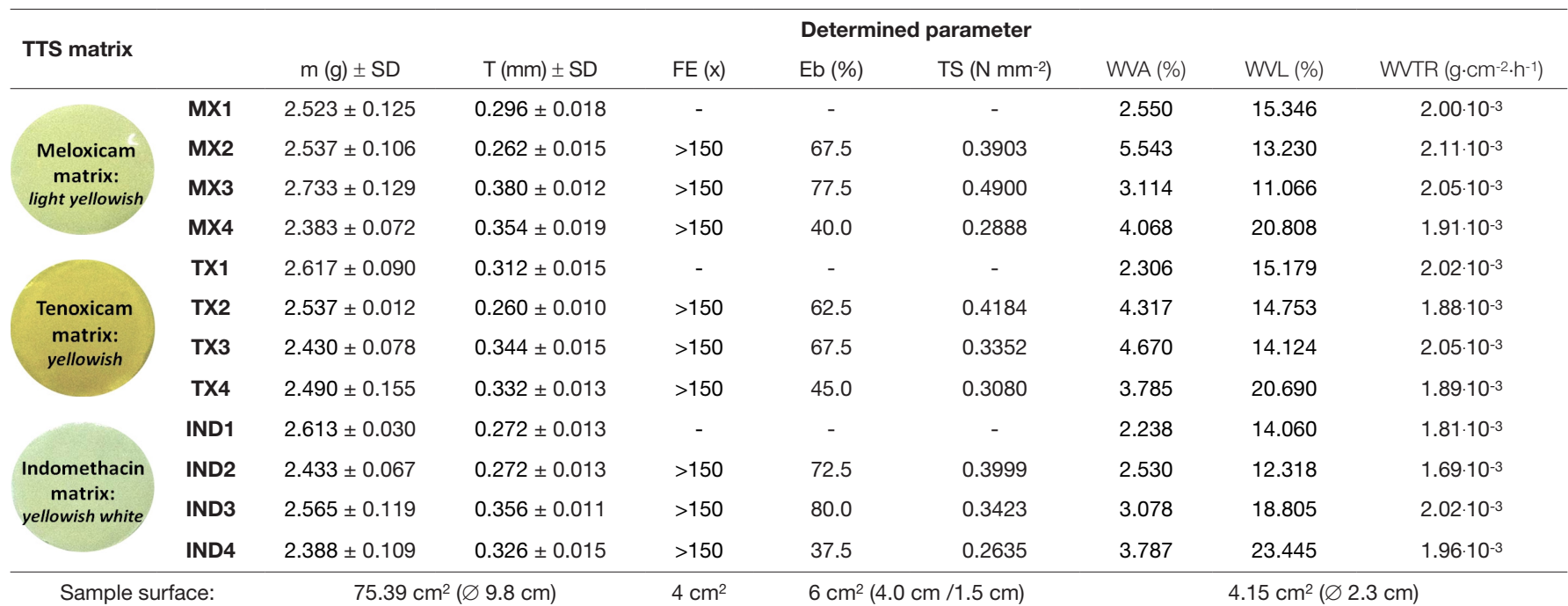

$\mathrm{m}=$ weight uniformity; $\mathrm{T}=$ thickness of matrix; FE = folding endurance $(\mathrm{x}=$ number of fold pairs until the break); Eb = elongation to break; TS = tensile strength; WVA = moisture vapor absorption; $\mathrm{WVL}=$ moisture vapor loss; WVTR = water vapor transmission rate; 
Table IV. Groups of data and calculated parameters subjected to analysis by statistical tests

\begin{tabular}{|c|c|c|c|c|c|c|c|c|c|c|}
\hline \multirow{3}{*}{ Parameter } & \multicolumn{10}{|c|}{ Mean value \pm SD } \\
\hline & \multirow{2}{*}{\multicolumn{3}{|c|}{ Group 1 (total) }} & \multicolumn{3}{|c|}{ Group 2} & \multicolumn{4}{|c|}{ Group 3} \\
\hline & & & & MX & TX & IND & TTS 1 & TTS 2 & TTS 3 & TTS 4 \\
\hline m & $\begin{array}{c}2.52 \\
\pm 0.10\end{array}$ & $\begin{array}{l}\text { a } p>0.10 \\
b p=0.72 \\
\text { c } p=0.68\end{array}$ & $\begin{array}{l}\text { ans } \\
\text { bns } \\
\text { c ns }\end{array}$ & $\begin{array}{c}2.54 \\
\pm 0.14\end{array}$ & $\begin{array}{c}2.52 \\
\pm 0.08\end{array}$ & $\begin{array}{c}2.50 \\
\pm 0.11\end{array}$ & $\begin{array}{c}2.58 \\
\pm 0.05\end{array}$ & $\begin{array}{c}2.50 \\
\pm 0.06\end{array}$ & $\begin{array}{c}2.58 \\
\pm 0.15\end{array}$ & $\begin{array}{c}2.42 \\
\pm 0.06\end{array}$ \\
\hline $\mathbf{T}$ & $\begin{array}{c}0.32 \\
\pm 0.04\end{array}$ & $\begin{array}{l}a p>0.10 \\
b p=0.54 \\
c p=0.67\end{array}$ & $\begin{array}{l}\text { ans } \\
\text { bns } \\
\text { c ns }\end{array}$ & $\begin{array}{c}0.32 \\
\pm 0.05\end{array}$ & $\begin{array}{c}0.31 \\
\pm 0.04\end{array}$ & $\begin{array}{c}0.31 \\
\pm 0.04\end{array}$ & $\begin{array}{c}0.30 \\
\pm 0.01\end{array}$ & $\begin{array}{c}0.27 \\
\pm 0.01\end{array}$ & $\begin{array}{c}0.36 \\
\pm 0.02\end{array}$ & $\begin{array}{c}0.34 \\
\pm 0.02\end{array}$ \\
\hline D & $\begin{array}{c}1.07 \\
\pm 0.14\end{array}$ & $\begin{array}{l}\text { a } p>0.10 \\
b p=0.24 \\
\text { c p }=0.16\end{array}$ & $\begin{array}{l}\text { ans } \\
\text { b ns } \\
\text { c ns }\end{array}$ & $\begin{array}{c}1.06 \\
\pm 0.18\end{array}$ & $\begin{array}{c}1.08 \\
\pm 0.16\end{array}$ & $\begin{array}{c}1.08 \\
\pm 0.13\end{array}$ & $\begin{array}{c}1.14 \\
\pm 0.04\end{array}$ & $\begin{array}{c}1.25 \\
\pm 0.06\end{array}$ & $\begin{array}{c}0.94 \\
\pm 0.01\end{array}$ & $\begin{array}{c}0.95 \\
\pm 0.05\end{array}$ \\
\hline $\mathrm{Eb}$ & $\begin{array}{c}61.11 \\
\pm 16.21\end{array}$ & $\begin{array}{l}\text { a } p>0.10 \\
b p=0.36 \\
c p=0.17\end{array}$ & $\begin{array}{l}\text { ans } \\
\text { bns } \\
\text { c ns }\end{array}$ & $\begin{array}{c}61.67 \\
\pm 19.42\end{array}$ & $\begin{array}{c}58.33 \\
\pm 11.81\end{array}$ & $\begin{array}{c}63.33 \\
\pm 22.68\end{array}$ & - & $\begin{array}{l}67.50 \\
\pm 5.00\end{array}$ & $\begin{array}{l}75.00 \\
\pm 6.61\end{array}$ & $\begin{array}{r}40.83 \\
\pm 3.82\end{array}$ \\
\hline TS & $\begin{array}{c}0.36 \\
\pm 0.07\end{array}$ & $\begin{array}{l}a p>0.10 \\
b p=0.78 \\
c p=0.88\end{array}$ & $\begin{array}{l}\text { ans } \\
\text { bns } \\
\text { c ns }\end{array}$ & $\begin{array}{c}0.39 \\
\pm 0.10\end{array}$ & $\begin{array}{c}0.35 \\
\pm 0.06\end{array}$ & $\begin{array}{c}0.34 \\
\pm 0.07\end{array}$ & - & $\begin{array}{c}0.40 \\
\pm 0.01\end{array}$ & $\begin{array}{c}0.39 \\
\pm 0.09\end{array}$ & $\begin{array}{c}0.29 \\
\pm 0.02\end{array}$ \\
\hline WVA & $\begin{array}{c}3.50 \\
\pm 1.04\end{array}$ & $\begin{array}{l}\text { a } p>0.10 \\
\text { b } p=0.68 \\
\text { c } p=0.49\end{array}$ & $\begin{array}{l}\text { ans } \\
b n s \\
c n s\end{array}$ & $\begin{array}{c}3.82 \\
\pm 1.31\end{array}$ & $\begin{array}{c}3.77 \\
\pm 1.04\end{array}$ & $\begin{array}{c}2.91 \\
\pm 0.68\end{array}$ & $\begin{array}{c}2.37 \\
\pm 0.16\end{array}$ & $\begin{array}{c}4.13 \\
\pm 1.52\end{array}$ & $\begin{array}{c}3.62 \\
\pm 0.91\end{array}$ & $\begin{array}{c}3.88 \\
\pm 0.16\end{array}$ \\
\hline WVL & $\begin{array}{c}16.15 \\
\pm 3.86\end{array}$ & $\begin{array}{l}a p=0.04 \\
b p=0.49 \\
\text { c } p=0.24\end{array}$ & $\begin{array}{l}a^{*} \\
b n s \\
c n s\end{array}$ & $\begin{array}{c}15.11 \\
\pm 4.18\end{array}$ & $\begin{array}{r}16.19 \\
\pm 3.03\end{array}$ & $\begin{array}{r}17.16 \\
\pm 5.01\end{array}$ & $\begin{array}{c}14.86 \\
\pm 0.70\end{array}$ & $\begin{array}{r}13.43 \\
\pm 1.23\end{array}$ & $\begin{array}{c}14.67 \\
\pm 3.90\end{array}$ & $\begin{array}{l}21.65 \\
\pm 1.56\end{array}$ \\
\hline WVTR & $\begin{array}{c}1.95 \\
\pm 0.12\end{array}$ & $\begin{array}{l}a p>0.10 \\
b p=0.26 \\
c p=0.49\end{array}$ & $\begin{array}{l}\text { ans } \\
\text { bns } \\
\text { c ns }\end{array}$ & $\begin{array}{c}2.02 \\
\pm 0.08\end{array}$ & $\begin{array}{c}1.96 \\
\pm 0.09\end{array}$ & $\begin{array}{c}1.87 \\
\pm 0.15\end{array}$ & $\begin{array}{c}1.94 \\
\pm 1.12\end{array}$ & $\begin{array}{c}1.89 \\
\pm 0.21\end{array}$ & $\begin{array}{c}2.04 \\
\pm 0.02\end{array}$ & $\begin{array}{c}1.92 \\
\pm 0.04\end{array}$ \\
\hline $\mathrm{Hf}$ & $\begin{array}{c}252.8 \\
\pm 232.3\end{array}$ & $\begin{array}{l}a p>0.10 \\
b p=0.04 \\
c p=0.04\end{array}$ & $\begin{array}{l}\text { a ns } \\
b s^{*} \\
c^{*}\end{array}$ & $\begin{array}{c}206.9 \\
\pm 189.6\end{array}$ & $\begin{array}{c}282.2 \\
\pm 354.0\end{array}$ & $\begin{array}{c}269.2 \\
\pm 179.8\end{array}$ & $\begin{array}{c}46.0 \\
\pm 22.2\end{array}$ & $\begin{array}{l}209.7 \\
\pm 60.0\end{array}$ & $\begin{array}{c}595.0 \\
\pm 183.6\end{array}$ & $\begin{array}{r}160.3 \\
\pm 59.8\end{array}$ \\
\hline Af & $\begin{array}{r}107.8 \\
\pm 43.4\end{array}$ & $\begin{array}{l}a p=0.02 \\
b p=0.31 \\
c p=0.05\end{array}$ & $\begin{array}{l}a^{*} \\
\text { b ns } \\
c^{*} s^{*}\end{array}$ & $\begin{array}{r}117.3 \\
\pm 59.2\end{array}$ & $\begin{array}{r}106.2 \\
\pm 53.5\end{array}$ & $\begin{array}{c}99.9 \\
\pm 18.2\end{array}$ & $\begin{array}{c}90.0 \\
\pm 33.1\end{array}$ & $\begin{array}{r}138.3 \\
\pm 50.9\end{array}$ & $\begin{array}{c}78.8 \\
\pm 17.1\end{array}$ & $\begin{array}{r}124.0 \\
\pm 53.5\end{array}$ \\
\hline A & $\begin{array}{c}0.19 \\
\pm 0.07\end{array}$ & $\begin{array}{l}a p=0.06 \\
b p=0.03 \\
c p=0.02\end{array}$ & $\begin{array}{l}\text { ans } \\
b s^{*} \\
c s^{*}\end{array}$ & $\begin{array}{c}0.25 \\
\pm 0.10\end{array}$ & $\begin{array}{c}0.18 \\
\pm 0.04\end{array}$ & $\begin{array}{c}0.15 \\
\pm 0.03\end{array}$ & $\begin{array}{c}0.16 \\
\pm 0.03\end{array}$ & $\begin{array}{c}0.23 \\
\pm 0.07\end{array}$ & $\begin{array}{c}0.16 \\
\pm 0.05\end{array}$ & $\begin{array}{c}0.22 \\
\pm 0.13\end{array}$ \\
\hline
\end{tabular}

$\mathrm{a}=$ Kolmogorov-Smirnov (KP) test, $\mathrm{b}=\mathrm{D}$ 'Agostino \& Pearson omnibus test, $\mathrm{c}=$ Shapiro-Wilk test:

ns = statistically insignificant; * statistical significant $(p<0.05$, for $\mathrm{Cl}$ of $95 \%)$

For the other products, their viscoelastic properties ensure an elongation of $61.11 \%$ under the action of the downward tensile forces, while the mechanical resistance at break is $0.36 \mathrm{~N} \cdot \mathrm{mm}^{-2}$ in terms of tensile strength and $252.8 \mathrm{~g}$ in terms of hardness force. In the case of the tensile strength, although the value of $p>0.1000$ calculated by Kolmogorov-Smirnov normality test suggests a population with normal distribution, the other two normality tests with $\mathrm{p}=0.0360$ (D'Agostino \& Pearson omnibus normality test) and $\mathrm{p}=0.0374$ (Shapiro-Wilk normality test) indicate the contrary. This anomaly can be explained by the significant influence of composition on the mechanical properties.

Exposed to humidity in form of vapors TTS matrices bound the water in the percentage of $3.5 \%$, while in dry atmosphere they lose $16.15 \%$ of their weight. The water vapor loss depends on the composition of the matrix, as the individual values vary significantly from a normal distribution ( $\mathrm{p}<0.05, \mathrm{KP}$ normality test). Transmission of humidity through the matrix from one to the other surface has a mean rate of $1.95 \cdot 10^{-3} \mathrm{~g} \cdot \mathrm{cm}^{-2} \mathrm{~h}^{-1}$ water vapors, in case of a moisture loss 5 times greater than the moisture uptake (WVA vs. WVL) under the given circumstances. These data indicate a predominant water loss on the surface exposed to air, even though the other side of the matrix surface is being exposed to humidity.
Adhesiveness of the film surface of $0.19 \mathrm{~mJ}$ was obtained by using about $107.8 \mathrm{~g}$ adhesive force. The adhesive force is given by the maximum of the negative force recorded on the graph, more negative the values of this parameter meaning better adhesion of the sample. The area under the curve until the zero line is used to calculate the adhesiveness and the force required to break the sample can provide information relating to the cohesion of the molecules in the sample.

The statistical normality tests applied reveal that the individual values of the adhesive force have a significant deviation from the average $(\mathrm{p}<0.05$, KS normality test), indicating a powerful influence of films composition on this parameter. As well as in the case of tensile strength, the dispersion from the average of adhesiveness values suggests a normal distribution by KP normality test $(\mathrm{p}>0.1000)$, while in contrary by the other two tests (D'Agostino \& Pearson omnibus test, with $\mathrm{p}=0.0291$; and Shapiro-Wilk test, with $\mathrm{p}=0.0190$ ), which also could be explained by the significant influence of matrix compositions on this dependent variable.

-The effect of NSAID type (table IV, group 2) vs. the effect of polymer matrix type (table IV, group 3) on the parameters of the NSAID TTS matrix, based on the analysis of the variance between groups: 
For each of the two groups of data arranged in columns in replicate values in side-by-side columns, the variance of individual values to the mean was analyzed by Two-way ANOVA test. Supplementary, each line had been compared (simple effects within columns) by Tukey's multiple comparisons test (figure 1).

In case of data grouped by polymer matrix type, the variance is significantly $(\mathrm{p}<0.0001, \alpha=0.05)$ determined by the matrix type (3.95\%). Type of the film forming polymer influences in an approximately equally measure all the experimental parameters considered as depended variables with the exception of hardness force - the highest variance, adhesive force and elongation to break - with slightly higher different variance (by Tukey test).

In case of data grouped by NSAID type, it can be stated that the effect of the NSAID type is insignificant $(0.94 \%)$ and appears in the same measure in the values of the analyzed experimental data. All the results suggest that hardness differentiates in a statistically significant way the 12 types of TTSs matrix, the rupture test results as average of data grouped by NSAID type being the following: $206.9 \mathrm{~g}$ for MX, 282.2 $\mathrm{g}$ for TX and $269.2 \mathrm{~g}$ for IND.

\section{Correlation of NSAID TTS matrix mechanical param-} eters:

Elongation of TTS matrix may be explained by the sliding capacity of matrix building polymeric layers, simultaneously with the resistance to movement of the polymeric chains, which after the elongation caused by a tensile forces, tend to regain their initial form.
The maximum of elongation previous to the rupture causing tension have the following values: $67.5 \%-0.40$ $\mathrm{N} \cdot \mathrm{mm}^{-2}$ for TTS 2 (HPMC 15000 1\%), $75.0 \%-0.39$ $\mathrm{N} \cdot \mathrm{mm}^{-2}$ for TTS 3 (1.5\% HPMC 15000) and $40.8 \%$ $0.29 \mathrm{~N} \cdot \mathrm{mm}^{-2}$ for TTS 4 (1\% HPMC $15000+1 \%$ EC 10$)$, respectively. The correlation grade of the two mentioned parameters was established by Pearson test individually for each product, as it is shown in figure 2 .

A significant correlation was demonstrated in all cases, as all Pearson $\mathrm{r}$ values are in the range of 0.9818 (the lower, in the case of IND4) to 0.9934 (the highest, in the case of MX3). The average of Pearson coefficients of TTS matrix grouped by NSAID type shows a superior correlation for meloxicam independently of the matrix type: $\mathrm{r} \pm \mathrm{CV}(\%)$ $=0.9905 \pm 0.2633$. On the other hand, in the TTS matrix grouped by polymer matrix type a superior correlation is shown in the case of TTS matrix 3 (formed by $1.5 \%$ HPMC 15000): with $\mathrm{r} \pm \mathrm{CV}(\%)=0.9919 \pm 0.1430$.

\section{Conclusions}

The texture and the surface properties (resistance to perforation and bioadhesivity) of the 12 products prepared in form of polymeric films are critically (statistically significant) influenced by the ingredients associated in their composition. HPMC 15000 used in concentration of 1 $1.5 \%$ with $0.5 \%$ MX, TX or IND confers to TTSs matrix adequate mechanical properties for dermal application. MX incorporated in the structure of the polymeric matrix favors its viscoelastic structure. EC 10 functions as plasticizer for the HPMC 15000 matrix and supports its bioad-

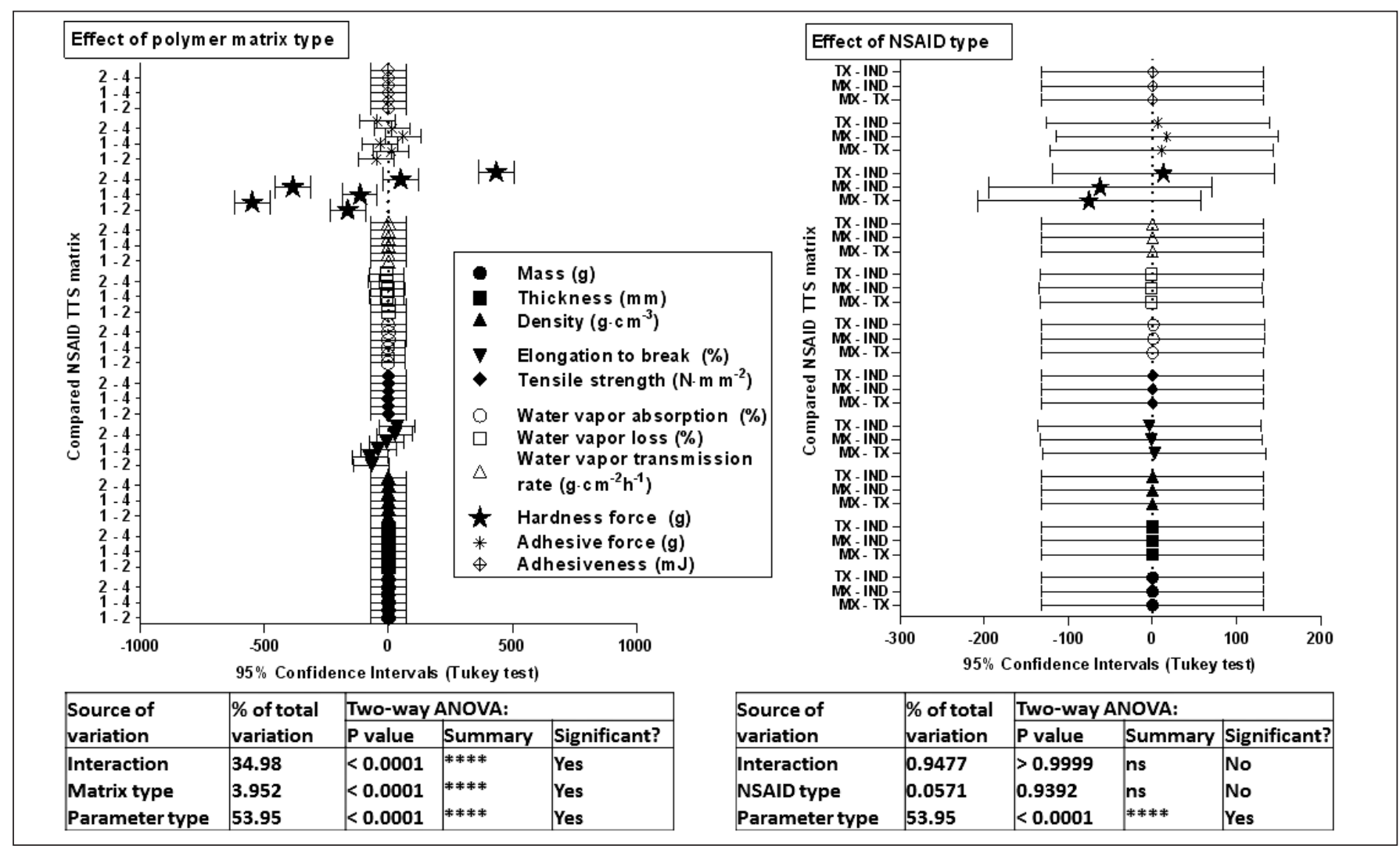

Fig. 1. Effect of polymer matrix type (group 3) vs. Effect of NSAID type (group 2) on the variance of NSAID TTS matrix parameters value expressed as average of experimental data 


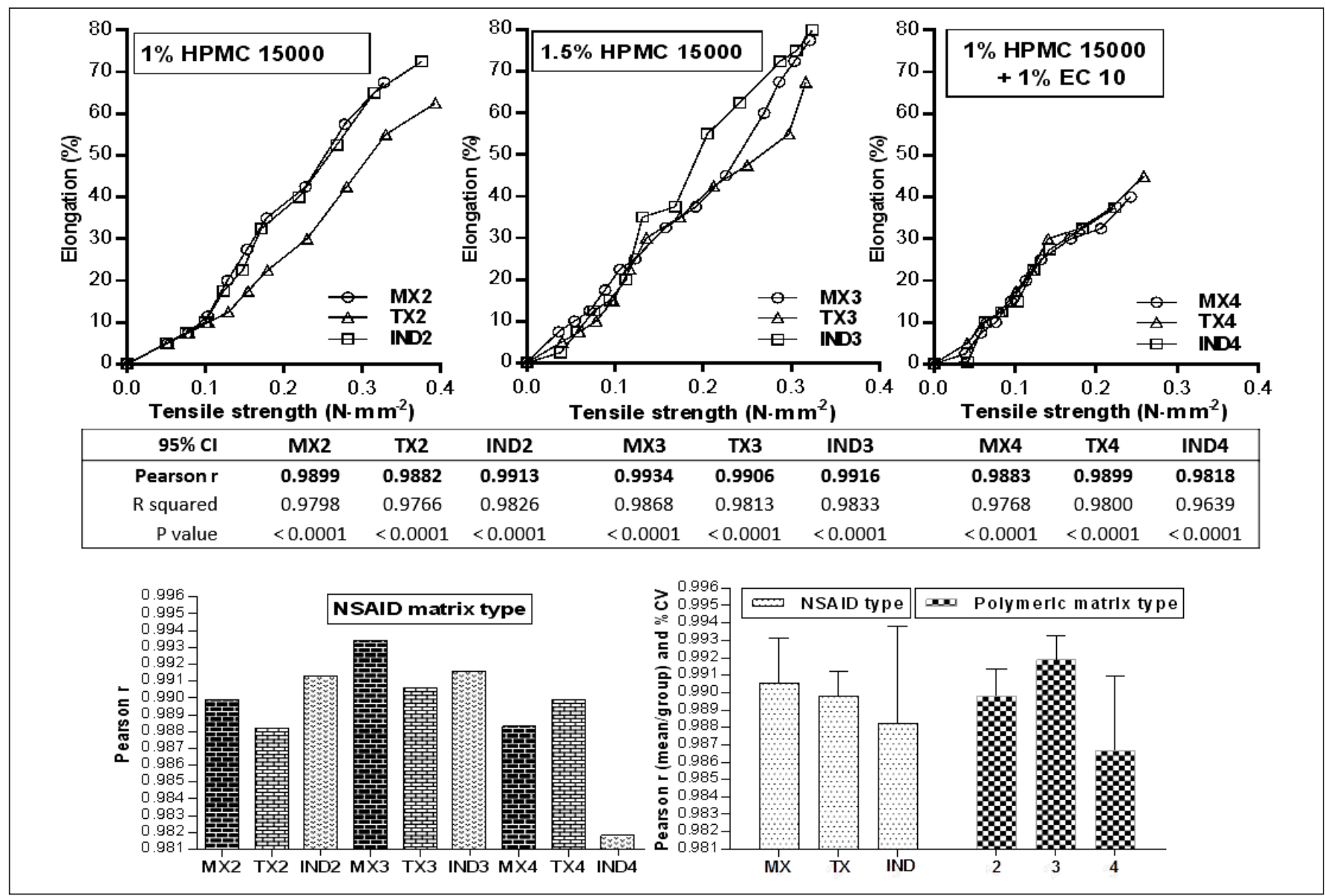

Fig. 2. Elongation of NSAID TSS matrix as function of tensile strength and the statistical significance of correlation by Pearson test: individual and average of grouped data

hesiveness. HPMC E5 3\% does not meet the requirements for TTS preparation in the used experimental conditions.

\section{Acknowledgments}

Preparation of products and evaluation of bulk viscoelastic properties were carried out with the financial support of Andofarm S.R.L. Company, through the internal grant 234/06.01.2016 of University of Medicine and Pharmacy of Tîrgu Mures, Romania.

Evaluation of texture and surface properties were carried out with the support of "Iuliu Hațieganu" University of Medicine and Pharmacy Cluj-Napoca, Romania.

\section{Conflict of interest}

None to declare.

\section{References}

1. Singh I, Morris AP - Performance of transdermal therapeutic systems: Effects of biological factors. Int J Pharm Investig. 2011;1(1):4-9.

2. Popovici I, Lupuleasa D - Tehnologie farmaceutică vol.2, București, Polirom, 2008, 841-888.

3. Patel D, Chaudhary SA, Parmar B, Bhura N - Transdermal drug delivery system: a review. J Pharm Innov. 2012;4:78-87.

4. Yadav $\mathrm{V}$ - Transdermal drug delivery system: review. Int J Pharm Sci Res. 2012;3(2):376-382.

5. Ting L, Changshun R, Manli W et al. - Optimized preparation and evaluation of indomethacin transdermal patch. Asian J Pharm Sci. 2007;2(6):249-259.
6. Jadhav JK, Sreenivas SA - Formulation and in vitro evaluation of indomethacin transdermal patches using polymers HPMC E5 and ethyl cellulose. Int J Pharm Pharm Sci. 2012;4(1):550-556.

7. Alladi S, Shastri NR - Semi solid matrix formulations of meloxicam and tenoxicam: an in vitro and in vivo evaluation. Arch Pharm Res. 2015;38(5):801-812.

8. Shirsand SB, Ladhane GM, Prathap S, Prakash PV - Design and evaluation of matrix transdermal patches of meloxicam. RGUHS $J$ Pharm Sci. 2012;2(4):58-65.

9. Nesseem D, Eid SF, El-Hosseny SS - Development of novel transdermal self-adhesive films for tenoxicam, an anti-inflamatory drug. Life Sci. 2011;89:430-438

10. EINabarawi MA, Shaker DS, Attia DA, Hamed SA - In-vitro skin permeation and biological evaluation of lornoxicam monolithic transdermal patches. Int J Pharm Pharm Sci. 2013;5(2):242-248.

11. Kavitha K, Rajendra MM - Design and evaluation of transdermal films of lornoxicam. Int J Pharm Bio Sci. 2011;2(2):54-62.

12. Parthasarathy G, Bhaskar Reddy K, Prasanth W - Formulation and characterization of transdermal patches of naproxen with various polymers. Pharmacie Globale International Journal of Comprehensive Pharmacy. 2011;6(7):1-4.

13. Verma N, Deshwal $\mathrm{S}$ - Design and in vitro evaluation of transdermal patches containing ketoprofen. World J Pharm Res. 2014;3(3):39303944.

14. Rastogi V, Yadav $\mathrm{P}$ - Transdermal drug delivery system: An overview. Asian J Pharm. 2012;6(3):161-170.

15. Snejdrova E, Dittrich M - Pharmaceutical applications of plasticized polymers, in Luqman M (ed.): Recent Advances in Plasticizers, Rijeka, Croatia, InTech Open Access, 2012, 69-84.

16. Güngör S, Erdal SM, Özsoy Y - Plasticizers in transdermal drug delivery systems, in Luqman M (ed.): Recent Advances in Plasticizers, Rijeka, Croatia, InTech Open Access, 2012, 91-105.

17. Kumar SV, Tarun P, Kumar TA - Transdermal drug delivery system for non-steroidal anti-inflammatory drugs: a review. Indo Am J Pharm Res. 2013;3(4):3588-3605. 